\title{
VIRTUAL RECONSTRUCTION OF LOST ARCHITECTURES: FROM THE TLS SURVEY TO AR VISUALIZATION
}

\author{
R. Quattrini ${ }^{\text {a* }}$, R. Pierdicca ${ }^{\text {b }}$, E. Frontoni ${ }^{\text {b }}$, R. Barcaglioni ${ }^{\text {a }}$ \\ ${ }^{a}$ DICEA, Dept. of Civil and Building Engineering and Architecture, Polytechnic University of Marche, Ancona, Italy - \\ r.quattrini@univpm.it, roberta_ba76@tin.it \\ ${ }^{\mathrm{b}}$ DII, Dept. of Civil and Building Engineering and Architecture, Polytechnic University of Marche, Ancona, Italy - (r.pierdicca, \\ e.frontoni)@univpm.it
}

Commission VI, WG VI/4

KEY WORDS: Point cloud processing, virtual anastylosis, augmented reality, roman archaeology, Vitruvius

\begin{abstract}
:
The exploitation of high quality 3D models for dissemination of archaeological heritage is currently an investigated topic, although Mobile Augmented Reality platforms for historical architecture are not available, allowing to develop low-cost pipelines for effective contents. The paper presents a virtual anastylosis, starting from historical sources and from 3D model based on TLS survey. Several efforts and outputs in augmented or immersive environments, exploiting this reconstruction, are discussed.

The work demonstrates the feasibility of a 3D reconstruction approach for complex architectural shapes starting from point clouds and its AR/VR exploitation, allowing the superimposition with archaeological evidences. Major contributions consist in the presentation and the discussion of a pipeline starting from the virtual model, to its simplification showing several outcomes, comparing also the supported data qualities and advantages/disadvantages due to MAR and VR limitations.
\end{abstract}

\section{INTRODUCTION}

The Roman archaeology is a valuable heritage of the European past, which needs tools that highlight its presence in our towns. Information and Communication Technologies (ICT) allows to "handle and enjoy" knowledge-based contents in several domains of cultural heritage and for all kind of users. Although Augmented Reality (AR) systems have demonstrated to be effective for Archaeological and Architectural Heritage's dissemination and its valorisation, it is not enough diffused. The recent increase of computational capabilities, as well as the advancement of sensor and 3D graphics technologies for handheld devices, offers the potential to make AR systems more useful to visualize high quality $3 \mathrm{D}$ data. Among others, virtual reconstructions of ancient artefacts no more existing are particularly suitable to be visualized with such technologies.

Integrating $3 \mathrm{D}$ virtual contents into $\mathrm{AR}$ environment could represent a milestone to make Digital Cultural Heritage $(\mathrm{DCH})$ more democratic and popular. The development of new digital tools has the main goal to provide users - insiders as well as nonexpert public - with instruments for the knowledge and in-depth study of historical heritage. Several works debate on suitability and performance of available Mobile Augmented Reality (MAR) platforms for historical architecture, pointing out the importance of developing low-cost pipelines for a wider exploitation of 3D models.

Following the Cyberarchaeology (Forte, 2010) paradigm, born for virtual environments in a museum, nowadays, it is possible to develop the "simulation process" on site, thanks to Augmented Reality (AR) applications. A critical key point is to maintain details and quality of obtained models when they are exported in mobile environment.

Given the above, we are presenting our approach towards CyberARchaeology, carried out in the Fano Roman Theatre, chosen as the case study of this dissertation, with a digital anastylosis starting from several sources.
The work presents a discussion about the use of 3D models, arising from accurate acquisition processes or reconstructions strictly coherent with historical sources, and their simplification to cope with MAR limitations. The work demonstrates the feasibility of a 3D reconstruction approach for complex architectural shapes starting from point clouds and its AR exploitation, allowing the superimposition with archaeological evidences. Some obstacles and challenges are still present and need further in depth analysis.

Due to hurdles in visualization of high-quality 3D models of virtual anastylosis in AR open source environment, the work proposes also a VR tool. This step allows an easy portability of level of details from the 3D model, although the perceiving is very different and not compliant with the main goals of our approach.

\section{STATE OF ART}

The increasing evolution of technology and the higher integration of survey techniques, such as laser scanning and photogrammetry, is widening the spectrum of applications for the Cultural Heritage $(\mathrm{CH})$ domain. The reason is that the creation of 3D models reconstruction would significantly enhance the promotion of archaeological sites and their artefacts.

Nowadays, relevant archaeological studies are strictly related to the use of state-of-art 3D acquisition technologies, and consequently, they cannot be conducted without the use of 3D archaeological models. The possible output arising from them are manifold: they can be developed in several levels of detail and/or representation scales from GIS to 3D Cognitive-Information System through a semantic modelling (Apollonio, et al., 2011); moreover, applying VR techniques allows simulating and storytelling about architectural monuments, starting from existing data (Pietroni, et al., 2015). Several examples demonstrate excellent results, obtained implementing realitybased 3D models: among the others, the 3D GIS Information

* Corresponding author 
System for Pompei (Gaiani, et al., 2011) and the project about Etruscan tombs (Remondino, 2011). Besides, in (Moitinho \& Barcelò, 2012) the use of 3D digital model and reverse engineering process were used to obtain significant data of archaeological evidences.

When dealing with virtual visualization techniques for the valorisation of archaeological landscape and heritage, it is mandatory to refer to the main Charters at international level: the London Charter (Haegler, et al., 2009) and the Seville Charter. The first one was conceived to enhance the rigour with which computer-based visualisation methods and outcomes are used and evaluated in heritage contexts, thereby promoting understanding and recognition of such methods and outcomes.

The second one, born as a consequence of the London Charter, has the aim of proposing specific implementation guidelines, in the field of Virtual Archaeology (VA). As stated in (Grande \& Lopez-Menchero, 2011). VA can immediately depict complex contexts relating to the past or forward readings of historical, architectural, territorial or social situations, becoming a valid contribution to the transposition of information, thus proposing a powerful instrument for the cultural diffusion. Several attempts have been carried out in order to provide researchers and insiders with a methodology for interpretation management, establishing a sound framework for creating and publishing 3D visualisation results. This implies improving their quality and preserving the investments and the intellectual efforts that have been spent to create them.

Notwithstanding, the necessity to improve the chain from acquisition to visualization is paramount. Actually, the majority of the 3D visualisation work of archaeological structures goes into the assessment and interpretation of the sources. This is due to the fact that:

- the interpretation process is complex and can extend over a long period;

- the amount of source data can be tremendously large;

- in many cases multiple people simultaneously work on the same project.

In this regards, validation and affordability check of the model should follow well-defined procedures, supported by a tool that records and manages this interpretation process; the aim, is to build a spatial-temporary environment able to reconnect the archaeological landscape with the ancient landscape, following a validated and transparent methodological path (Borra, 2004).

Despite the interpretation of data is, as said, a fundamental task, also their communication and dissemination should be taken into account at a very early stage of the whole pipeline. This is because the huge amount of 3D data, as well as the high quality of contents, require specific strategies to ensure a complete exploitation of the archaeological heritage. The implementation of strategies is entrusted to the use of ICT, especially through mobile applications, which embrace all the quality for this approach.

The latter, in the last decade, are carrying successful influence by increasing the interest of people for both museums and archaeological sites. Visitors can be provided with information and contents about the exhibition, with smart and low cost procedures (Gerval \& Le Ru, 2015). Furthermore, by creating an enriched narrative process thanks to multimedia cultural, the so called storytelling, the potential offered by digital tools for editing and disseminating contents can be farther exploited, as demonstrated by several studies (Laudazi \& Bocaccini, 2014). The increasing potential of mobile devices (e.g. sensors or advancement of 3D accelerated graphics) also boosted the adoption of Augmented Reality experiences, which have proved to be a valuable solution for Cultural Heritage purposes.

AR technology enhances the perception of the real world by overlaying digital contents on the real world, with the aim of persuading the viewer that the virtual object is part of the real environment (Haugstvedt \& Krogstie, 2012). AR offers the potential to make heritage systems more comfortable to carry and wear, facilitating the spread of this kind of AR systems to the mass market. (Brondi, et al., 2012). The diffusion of software platform for the development of AR experience, made possible the use of Mobile Augmented Reality (MAR) for several research fields (Vanoni, et al., 2012).

Of course, also archaeological sites can benefit from this kind of applications. The main contributions of using AR in this field are many, even if the more remarkable are way-finding services and context-awareness, in order to make visit of unknown spaces more accessible and enjoyable (Choudary, et al., 2009).

By combining historical and archaeological details, for instance, the user experience can be improved by imaging the archaeological ruins with the ancient landscape (Bernardini, et al., 2012). Another important project to be mentioned is ARAC Maps (Eggert, et al., 2014). The objective was augmenting archaeological maps using 3D models together with other interactive approaches.

The examples reported in this section underpin a basic assumption: for the development of $\mathrm{AR}$ experiences for architecture, landscape and archaeology is necessary an interdisciplinary team, allowing a responsible and efficient use of ICT and computer-mediated reality in knowledge-based experiences about cultural heritage (Empler, 2015). Since the development of new digital tools is aimed at providing insiders and non-expert public with useful and effective instruments for the knowledge and dissemination of artistic and architectural heritage, the integration of cutting edge technologies (i.e. Augmented Reality) with 3D virtual contents could represent the turnkey in which $\mathrm{CH}$ is exploited.

\section{METHODOLOGY}

The paper takes in account different technical issues regarding: a) acquisition phase, b) modelling and shapes reconstruction, c) reduction and balancing of detail (such as polygonalization), d) segmentation and semantic organization e) visual and light appearance (texturing or ambient occlusion) and other topics related to the challenges in development of AR three-dimensional browsing. Technical choices and visual results will contribute to define the technological framework mainly based on mobile systems, aiming to offer an expandable "open data" experience of Archaeological Heritage.

\subsection{The architectural survey and the positioning of evidences in the Archeofano project}

The selected case study is the Roman Theatre of Fanum Fortunae (modern: Fano) in Italy: for this important example of the roman heritage of the Fano town, a Terrestrial Laser Scanner (TLS) survey was carried out (

Figure 1) and then a virtual reconstruction was conducted, taking into account archaeological samples, geometrical survey of evidences, praxis and theory of roman architecture.

The work proposed in this paper is part of a wider project named "ArcheoFano", which has the main objective of collect, organize and manage remote sensed data about ancient artefacts belonging to several archaeological sites, scattered among the town. The development of a GIS platform allowed to store, with related attributes, complex architectures like the roman theatre, subject of this dissertation. Considering each complex as a Point of Interest (POI), it was possible to retrieve geo-localized information and exploit them into AR fashion environment.

The Theatre's remains are actually inaccessible for the public and a particular attention was paid to its survey: the first stage idea was to use AR technology to visualize the virtual TLS model as 
it appeared after the excavation allowing to browse it with the same location of the evidences.

After the work of reconstruction, described in the following section, the further step would be to visualize it in the real position, as it appeared at the time of its construction.

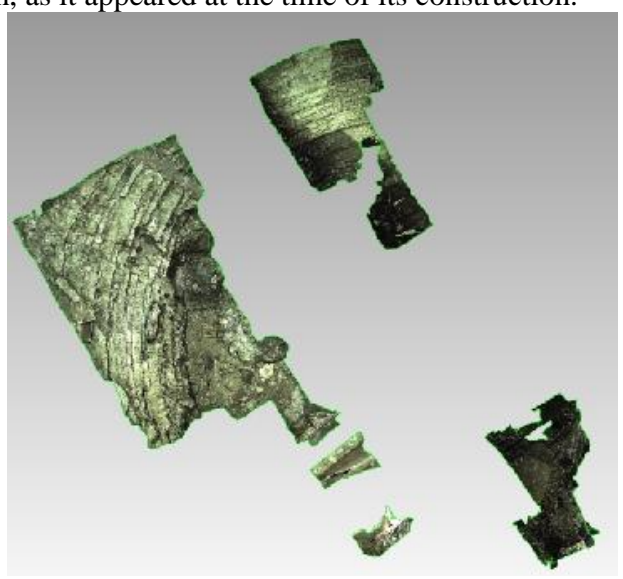

Figure 1. Mesh of TLS point cloud

\subsection{The virtual reconstruction}

In a second step, a virtual reconstruction of a Roman Theatre was built with data arising from an urgent partial excavation, while the complete $3 \mathrm{D}$ virtual model is an interpretation based on several sources, mostly on the Vitruvius Treatise. The process consists of a digital anastylosis starting from historical and metric sources, highlighting the choices in the modelling phase.

Starting from the TLS point cloud and archaeological samples, we segmented and annotated the mesh model for the first classification of main elements of Theatre (Figure 2).
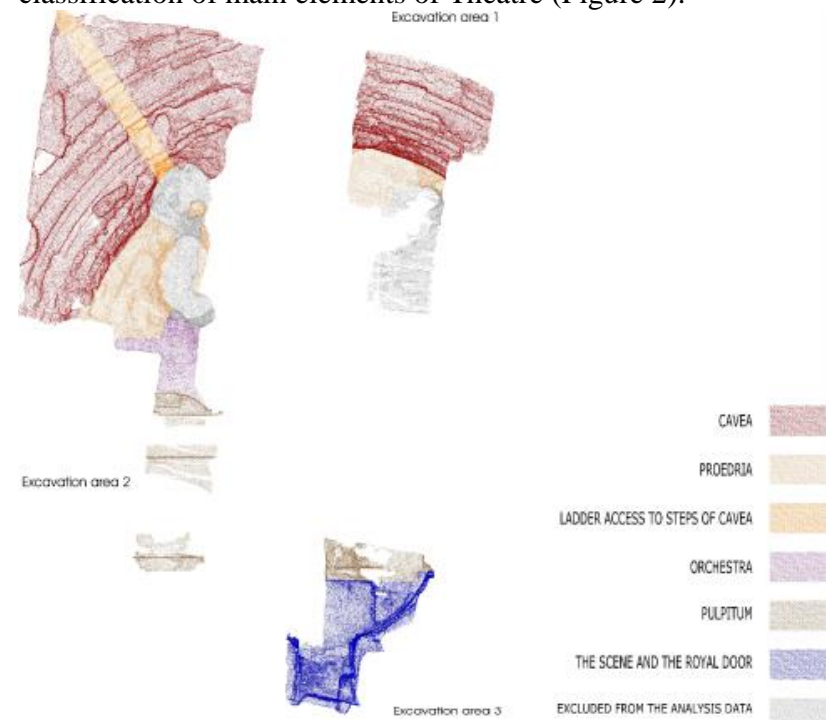

Figure 2. Segmentation of 3D mesh model in main tipological elements

In this paragraph the reconstruction choices about some parts are analysed, as follow: a) the cavea; b) the orchestra that contains the proedria $; \mathrm{c}$ ) the pulpitum and the curtain d) the scene and the royal door.

The first is certainly the part for which more data are present in archaeological evidences: for points cloud we draft the curve of steps reconstructing the main shapes of the cavea (Figure 3).
Thanks to original blocks, still visible, we obtained more geometrical information (Figure 3, Figure 4). These blocks have a size of about $30 \times 40 \mathrm{~cm}$. The seats have a width of $74 \mathrm{~cm}$, while the raised range from 29 to $34 \mathrm{~cm}$. There is also a gap $(40 \mathrm{~cm})$ between the cavea and the orchestra, allowing to separate the space (Figure 5).

In the points cloud (D sample) the staircase accessing to the cavea is clearly visible, presenting the same brick block. The stair case is $90 \mathrm{~cm}$ large. For the whole elevation of the Theatre we used the previous shapes and added a summa cavea steeper, as Vitruvius suggest in its treatise.

Another staircase was symmetrically positioned with the previous one and we added also a central staircase between these last. In the upper part of the cavea the staircase are alternated to the lower, as typically occurs.

These stairs give access to the first surrounding corridor separating the galleries of a theatre; the exits are large 1/6 of rhe orchestra diameter.

Corresponding to the gap between cavea and proedria (seat of honor directly in front of or around the orchestra) there is a vertical block, obstructing to merge diverse social classes. The orchestra in the De Architectura is the central element around which the theatre is built: in this case study the orchestra contains the proedria which is the theatre venue for the most illustrious spectators such as Senators. It was found that the proedria was divided into 4 levels of height between 7 and $10 \mathrm{~cm}$, which correspond to the height of the stone used for its realization. In the sample E, near the pulpitum and side exit, archaeologists gathered the stone elements related to the pavement.

In front of the pulpitum it is a red marble slab (crushed) surrounded by marbles of two different colors. The marble strip that runs parallel to pulpitum is grey sky, while the perpendicular is grey white. Near the side access corridor, there are other gray heavenly pavement portions.

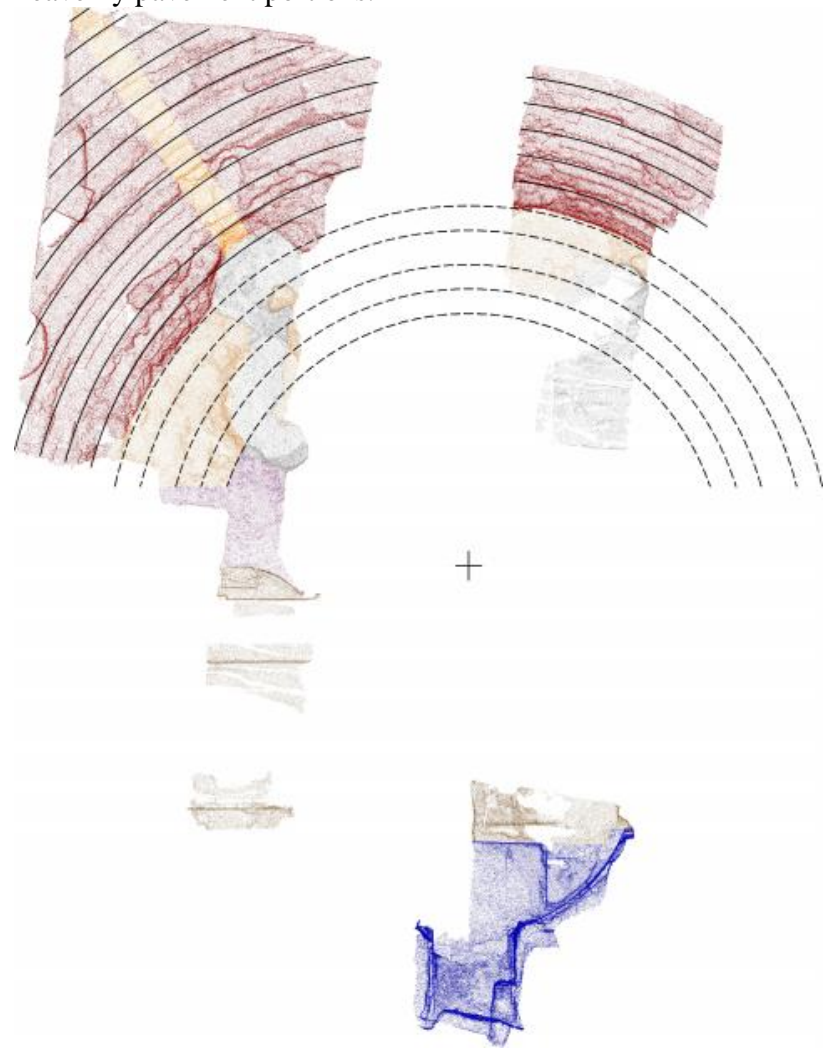

Figure 3. Drawing on the points cloud of cavea curve 


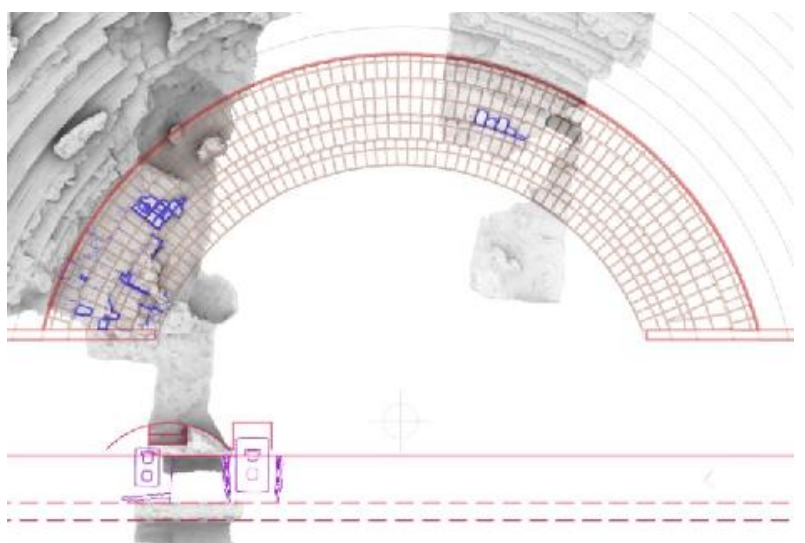

Figure 4. Reconstructed plan of Fano's Theatre

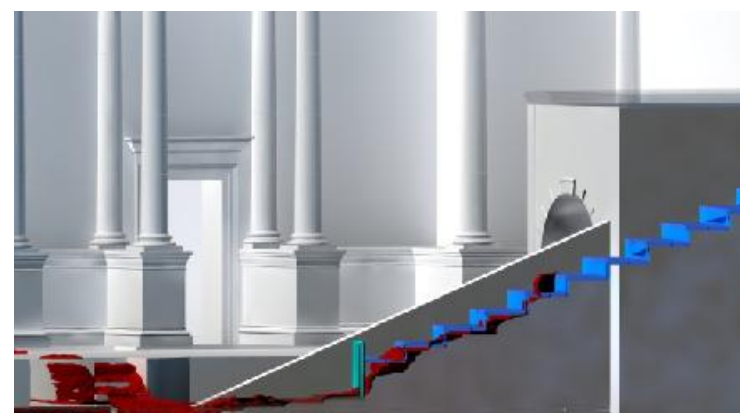

Figure 5. The gap between cavea and orchestra

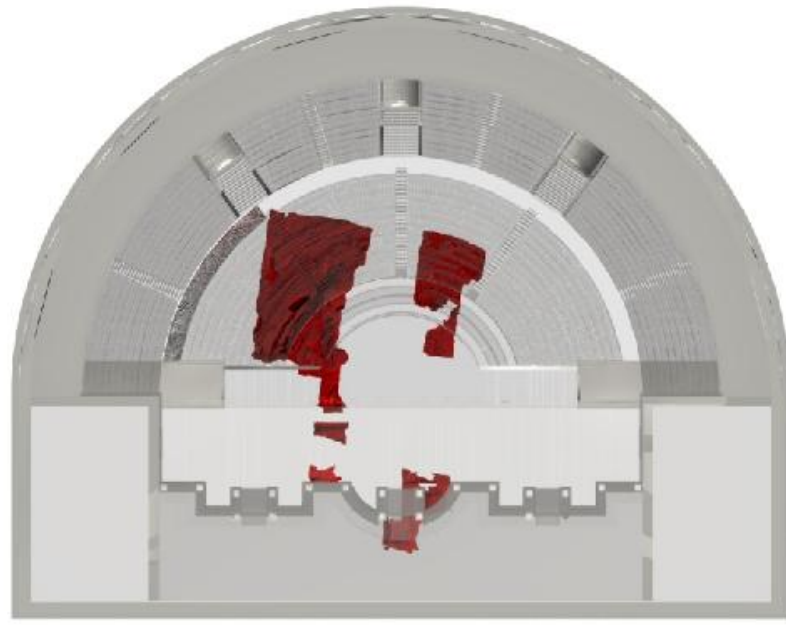

Figure 6 . The reconstructed map of the theatre and the archaeological evidences

These information were relevant for the materials and the textures. The Figure 6 shows the superimposition between existing evidences and the whole reconstruction of the theatre. De Architectura does not offer many elements for reconstructing the stage, including the pulpitum area. Real data showed that the top surface of the curve element (portion of pulpitum) present in the excavations is in line with the center of the orchestra. There are also three parallel walls, with a height similar to the pulpitum one. Between them, there is place for scenic equipment.

Near the walls, the archaeologists found two limestone slabs, with rectangular hole for beam.

We arranged the pulpitum symmetrically with the orchestra center and we supposed it rich and covered with polychrome marbles.
No much elements of the scene are in place, so the main proportions of the Vitruvian norm were used in its construction. The center of the royal door is aligned with the center of the circle describing the orchestra.

Two walls, supposed in line with the royal door, are still visible and covered by fragment of plaster and some stone parts.

Maybe the order of the columns was the Corinthian, because of in the archaeological excavation of the royal door was found a fragment of a pink capital Corinthian, now conserved in the city museum. The consistencies between excavation and model are shown in Figure 7.

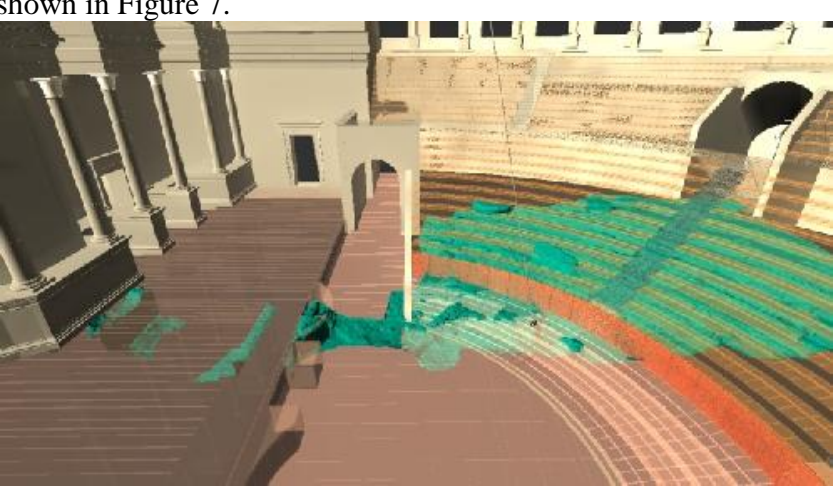

Figure 7. Overlapping 3D model and mesh of survey.

In the modeling of the elements that no longer exist we used the precepts of the Treaty and data emerging by recent studies about theatres in the same region (middle Adriatic).

The theatre was probably two orders, and medium-sized theaters like that of Gubbio had a second open portico at the level of the highest part of the summa cavea.

This reconstruction of the theatre of Fano, assuming the presence of a velarium was necessary to create a closed loop of masonry above the second portico, which contained the stone fasteners vertical wooden beams that supported the ropes and the rods of curtain (Figure 8).

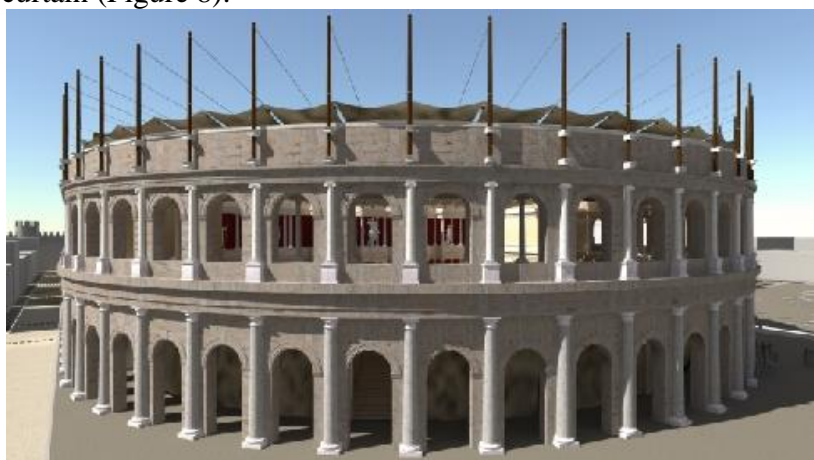

Figure 8. External view of the virtual reconstruction of theatre.

The external façade of the theatre, similar to other Middle Adriatic area (Gubbio-Teramo), could be covered in stone. The blocks of stone were rectangular in shape, but not finished and rough. For the stone, we choose the Furlo's stone, the same covering the Augustus Arch at Fano. Due to day-time use of the theatre, usually the velarium was present: a fabric covering or awning used to shade the audience in the cavea.

For this part of reconstruction, previous studies (Monterroso, 2010), (Madeleine, 2015) indicated main solutions: we arranged a velarium with ropes and pulley.

The ropes of the awning are fixed to the wooden beams speculated in turn anchored and clamped in the wall of the outer face of the top of the theater. Some anchors are also positioned in the orchestra. The curtain moves through a system of pulleys placed above the last portico (Figure 9). To support this 
mechanism it assumes a wall facing the top with a height of about 5 meters, from which soar the length beams up to 8- 10 meters.
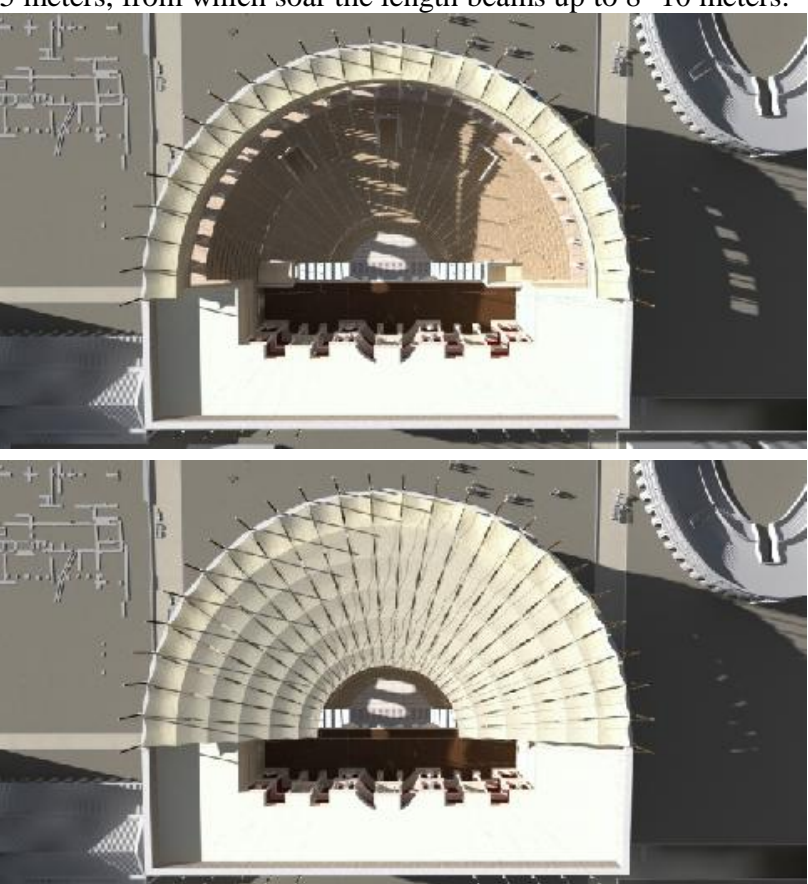

Figure 9. Aerial view of the virtual reconstruction of theatre, with open and closed velarium

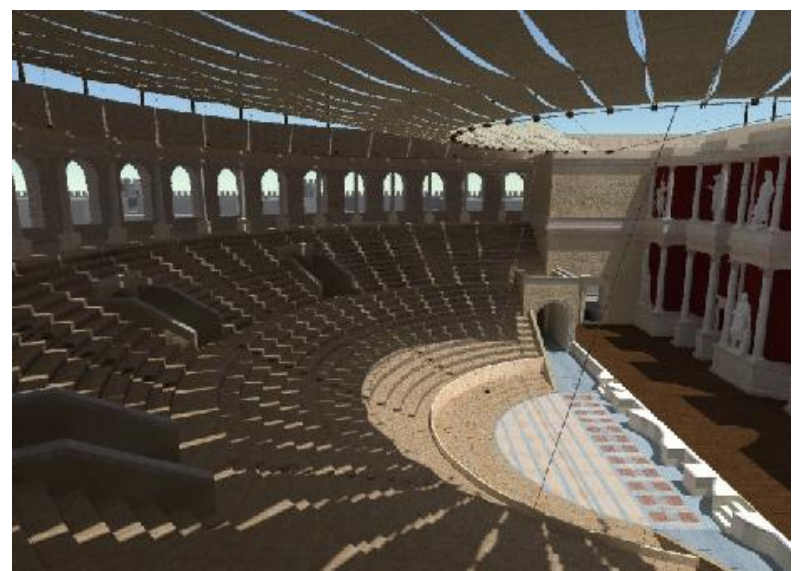

Figure 10. View of the cavea with open and closed velarium

\subsection{The AR and VR tools development}

Given the results obtained from of the previous phase, the main challenge is providing users with smart tools to visualize and experiencing the virtual artefacts. The possibility to "augment" the real world thought computer generated contents opens up new opportunities for the cultural dissemination and can lead towards an intuitive access to relevant information, enhancing the impact of the exhibition (Clini, et al., 2014). In fact, it is well known that several findings belonging to archaeological sites cannot be exposed to the public due to conservation issues. Hence, to prevent them from the definitive destruction, are quickly covered after their discovery. Thanks to the 3D reconstruction instead, ancient places can be virtually reopen, by giving the visitor an $\mathrm{x}$ ray view of the site and allowing the contextualization of those findings (Pierdicca, et al., 2015).

\footnotetext{
${ }^{1}$ http://vcg.isti.cnr.it/LecceAR/
}

Nowadays, the introduction of AR functionalities within mobile applications is increasing, especially for tourism purposes, since they are able to provide visitors with way finding services and contextual information (among others it's worthwhile to mention LecceAR ${ }^{1}$ and CorfuAR ${ }^{2}$ ). There are several reasons the growing interest for this kind of tools: first and foremost, mobile devices are more powerful and their computational capabilities allow the visualization of more complex information. Secondly, infrastructures (e.g., satellite localization, internet access, device capabilities) are increasingly available also in outdoor scenario. This implies that tourists visiting a certain area, are enabled to access to several context information, seeing them overlaid on top of the camera view through virtual annotations

Obviously, content typology and contextual information depend on the purpose of the application. Actually, the easy way to achieve a location-based experience is the publication of georeferenced Points of Interest (POIs) that can be used as descriptions of tourist attractions, displayed as simple geo-layer with textual information. The best solution would be to store the $3 \mathrm{D}$ models in a remote repository and retrieve them at user request, according to him/her position.

In this light, in the following we describe the digital outputs, obtained for the same artefact, developed in the last months: a) an AR visualization of survey data of archaeological finding $b$ ) two pipelines of MAR visualization for the whole model c) a VR visualization based on google card board and a app service

a) AR visualization of survey data

As a first step of the application, we decided to perform the AR visualization of the 3D mesh obtained from the TLS point cloud of the remains.

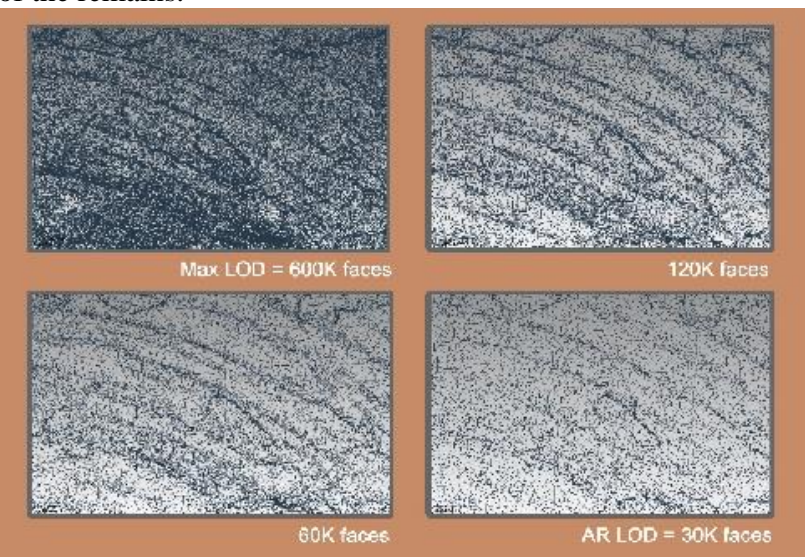

Figure 11. LOD of 3D model about archaeological data of Fano's Roman theatre

In this case, and more in general when dealing with 3D realitybased models, the most challenging task is to keep the right balance of data quality (e.g. weight) and its portability in mobile environments. This implies a tidy process of mesh simplification (Figure 11) in order to achieve a good visual appearance of the models, despite the need to contain the polygons number and the textures size into a limited range. Starting from a survey based on TLS point cloud, the max LOD of the survey model was 602540 faces, with a model dimension of $834 \mathrm{Mb}$ and a texture dimension of $54 \mathrm{Mb}$. The AR LOD about the whole model is a medium LOD: 30058 faces, an obj format file of $2 \mathrm{Mb}$ and a texture of 4,5Mb.

\section{b) AR visualization of $3 \mathrm{D}$ reconstruction}

In the second case, the application gives priority to the visualization of the 3D reconstructions of architectural heritage, based on resources from historical archives, exploiting the model generated with the methodology described. With respect with the

\footnotetext{
${ }^{2}$ http://www.corfuar.com
} 
previous case, the main difference is the 3D model typology. Herewith, in fact, the management of geometrical reconstruction requires a more accurate export phase. The capabilities of the AR browser also have to be taken into account during the development of the app. Only a restricted number of faces (surfaces) can be managed, hence the models have to be of reduced complexity to run smoothly on mobile devices. And more, achieving the expected visualization result implies a strict process of simplification of the models.

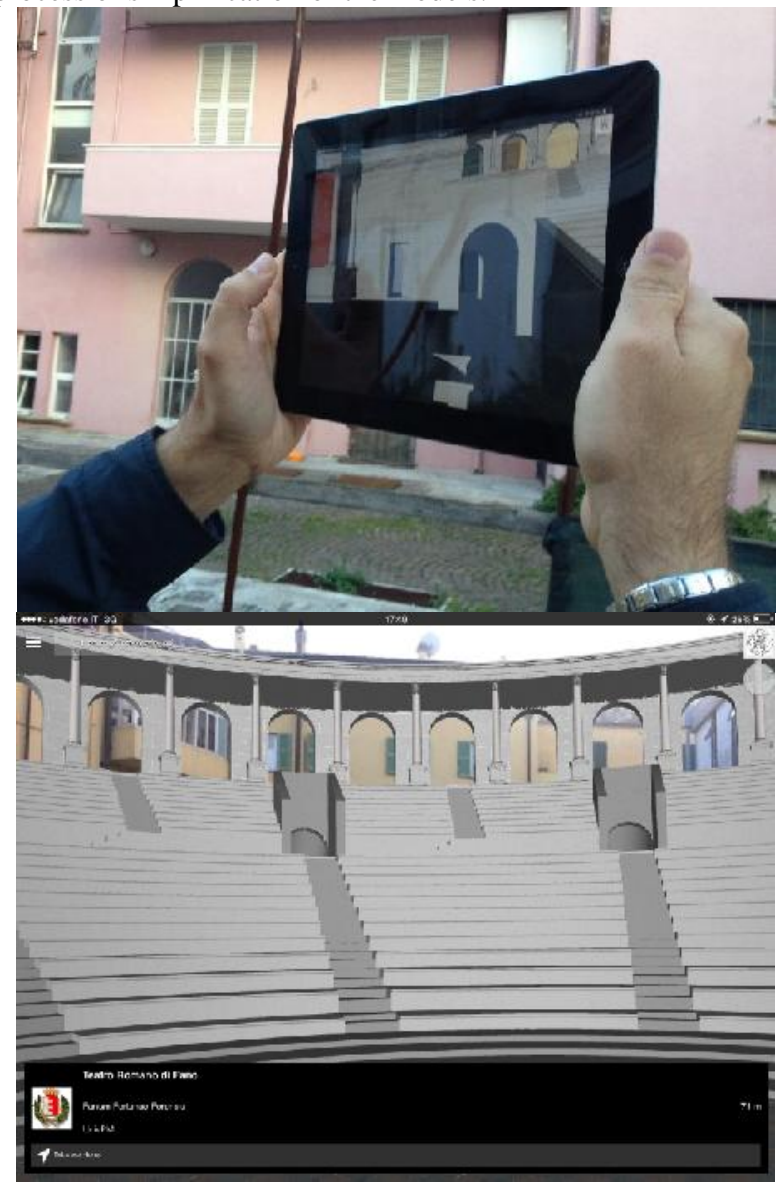

Figure 12. The development of MAR visualization for the whole reconstructed model using Layar

The use of several materials (i.e. textures), matching with multifaceted geometries, makes the visualization for mobile devices difficult. Exporting the model from a 3D modelling software generates in output three files: object, textures and coordinates. All these files should be stored into the same folder and the quality of visualization, hence the result, is strictly dependent on the capability of the mobile device.

In both a) and b), the applications were build by using Layar, a commercial framework specifically designed for AR. To achieve the result showed in Figure 12 we proceeded according to the following steps; the 3D model was exported as ".obj", the most common format to be managed into $3 \mathrm{D}$ environments, since it can maintain the original file object and the possibility of being edited.

The raw ".obj" file needs a further conversion. The "Layar converter" tool, provided with the Layar SDK, converts the ".obj" file into a format suitable to be managed in AR like a POI. Furthermore, the new ".13d" file was uploaded into the webservice and defined as a geo-layer. For the correct registration of

\footnotetext{
${ }^{3} \mathrm{http}: / /$ droidar.blogspot.it/
}

the model into the real environment, geometrical transformations (e.g. $6 \mathrm{DOF}$ and the scale factor), geo-location information (latitude, longitude and elevation) and the description are store into the table, specifically created to contain them.

Within the circle of specified radius, the application seeks for relevant POIs, starting from user's location. Once the user gets into the area of influence, the application can retrieve context information and visualize the 3D model in the exact position of the excavation.

However, this tool permits, at an entry level, to exploit the AR functions only thought a web browser, which don't allow the interaction by the user. To achieve this result, the development of a built in application is required, as reported in the next point. Even if the use of an interactive AR browser allow the user to discover geo-tagged information around him, there are several limitation in terms of interaction. More in deep, the model can be visualized, but gestures like pinch, zoon and move can be obtained only with the development of an ad hoc application. The concept is to perform a segmentation of the model, making each subpart editable by the user. To develop these features, we used the open source DroidAR ${ }^{3}$, an Augmented Reality library which covers a lot of common AR tasks, such as marker recognition, geo-location and landmarks, placing or collecting objects, drawing different shapes, simplifying the conversion from world to virtual coordinates and handling camera functionality. The visualization of the 3D model is related to the use of GDXLib ${ }^{4}$, specifically developed for the visualization of 3D models into mobile devices. State-of-art open source platforms are not mature enough to be used at professional level, while only commercial solution permit to achieve good results.

\section{c) $\mathrm{AR}$ visualization of $3 \mathrm{D}$ reconstruction}

For the VR output, we used a commercial tool as versatile photosphere viewer for Google Cardboard and Android Phone. This app supports both stereoscopic photospheres and panoramic traditional views. It allows to create virtual galleries and tours: the browsing between photospheres is performed through head movement or magnetic input. The standard procedure for the VR tool (Figure 13) about the Roman theatre of Fano follows the steps: 1) render to panoramas (equi rectangular format is preferred) 2) creation of an epipolar view modifying the initial panorama 3) upload in a mobile environment, supporting android 4) creation of the gallery.

\section{DISCUSSION AND RESULTS}

The use of Augmented Reality (AR) in a museum or for archaeological excavation, not still exhibition, holds great potential. Until now, introducing AR into their heritage has been prohibitively expensive for most museums and cultural institutions. Thanks to benchmarking and diffusion of several AR engines, the creation of cultural experience and learning has become easy, relatively fast and cheap. The skills associated with content creation might be the major effort to obtain effective AR tools. On the other and, the management of 3D contents is still a weak and time-consuming point in many approaches.

If $\mathrm{AR}$ tools will allow a more robust management of $3 \mathrm{D}$ complex contents, we highlight advantages from this kind of tools both for cultural institutions, insiders and tourism application:

a) the first tool enables to show the archaeological excavation during the time in which are not available, because covered by provisional textile.

b) a global visual experience of the model is provided, as well as the space appeared during the Roman time

c) each tool performs and facilitates a knowledge-based experience for learning interaction of users. 
d) the immersive experience stimulates powerful and lasting memory learning activities, facilitating so hurdles issues as well as non-existing architecture and its modelling work.

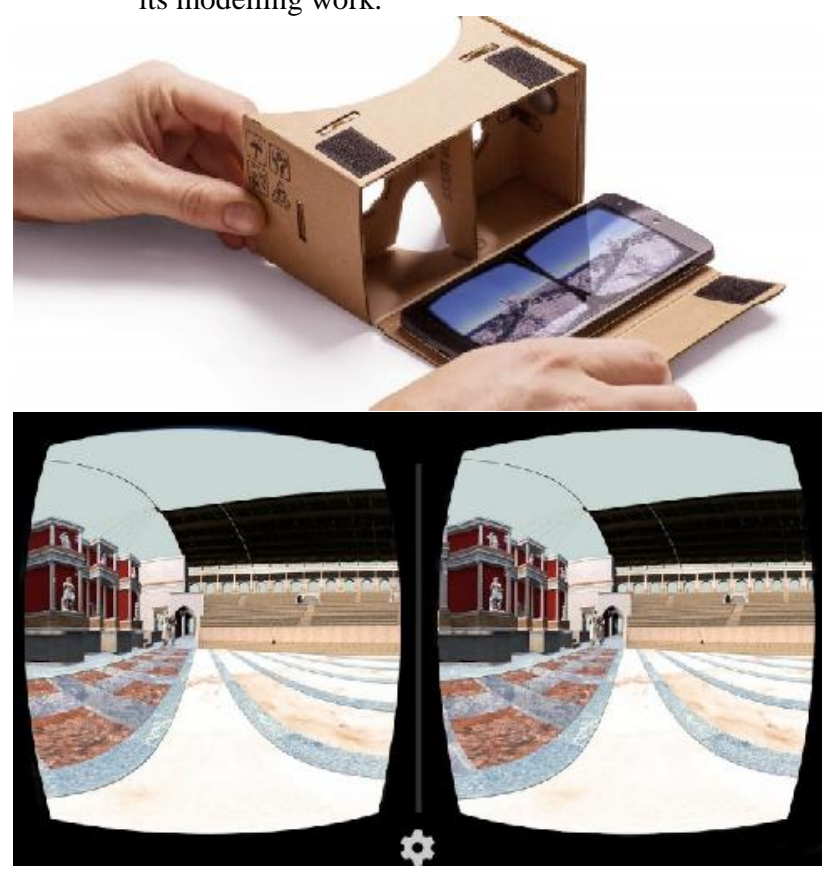

Figure 13. The VR application, allowing to explore full dome views of 3D model wearing Google Cardboard

Notwithstanding, the process of dissemination of AR for the abovementioned tasks is still in its infancy (Gartner, 2015). The motivation of this can be found in a set of impediments, challenges and obstacles that is needful to discuss. User location is based on the GPS and inertial sensor built into commercially available device where the accuracy is low. Even if the positioning output is error prone, after several adjustments (in terms of scale and coordinate) we reached a satisfactory result.shows the AR visualization of the $3 \mathrm{D}$ model in the same location of the Roman findings.

The quality of the obtained outputs is compared in Table 1 .

\begin{tabular}{|l|c|c|c|}
\hline Tool & \multicolumn{3}{|c|}{ Quality of 3D model } \\
\hline \multirow{3}{*}{ AR a) } & faces & weight & texture \\
\cline { 2 - 4 } AR b1) & 30058 & $2 \mathrm{Mb}$ & $4,5 \mathrm{Mb}$ \\
AR b2) & 391532 & $35 \mathrm{Mb}$ & $6 \mathrm{Mb}$ \\
\hline & 1743818 & $70 \mathrm{Mb}$ & $10 \mathrm{Mb}^{*}$ * 5 \\
\hline VR & \# of panoramas & weight & texture \\
\hline
\end{tabular}

Table 1. LOD and quality of models in various output

For the AR built in application (b2), we provide a first segmentation for AR output of the model, allowing to connect consistent contents without huge fragment the model. This segmentation foresaw five sub-parts of the model, as follows: orchestra, cavea, stage, external arcades and velarium (Figure 14). Were also defined additional content to link to each individual part. At this initial stage, our tests demonstrate several limitations, especially related to the management of 3D model into mobile devices. In fact, only a limited number of faces and vertex can be managed. Besides, common rendering parameters (e.g. transparencies or lighting), precluding a good visual appealing. Also textures presents some problems: in fact, only one texture can be managed for each subpart. For this last issue we improved each sub-part of the model with a the texture baking procedure, that gives chance to create texture maps based on an object's appearance in the rendered scene and its geometry. Disadvantages became from large textures (eg 4096x4096), because they are memory intensive and does not support each visualization needs regarding the resolution of fine details. Although, we obtained a first segmentation of 3D model, preparatory to a digital object linking multimedia information and able to answer query, because semantical-aware.

\begin{tabular}{|c|c|c|}
\hline \multicolumn{3}{|c|}{$\Delta \approx 0$ TEATRO_ARCATE obj } \\
\hline & File & TEATRO_ARCATE.obj \\
\hline & Faces & 563832 \\
\hline & Vertices & 272702 \\
\hline \multirow[t]{4}{*}{$\Delta+$} & 1 TEATRO CAVEA.cbj & 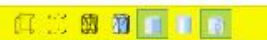 \\
\hline & 「ile & TГATRO_CAVTA_nbj \\
\hline & laces & 393804 \\
\hline & Vertices & 204833 \\
\hline \multicolumn{3}{|c|}{ 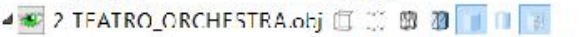 } \\
\hline & File & TEATRO_ORCHESTRA.uLj \\
\hline & Fates & 71576 \\
\hline & Vertices & 34675 \\
\hline \multirow[t]{4}{*}{$\Delta=$} & 3 TEATRO_SCENA.OBj & 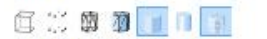 \\
\hline & Hilc & I $L A I K O S C E N A . O b J$ \\
\hline & Faces & 191860 \\
\hline & Vertices & 97271 \\
\hline \multirow[t]{4}{*}{$\Delta$} & 4 ILAIIRO_VLLAIIIO ObJ & 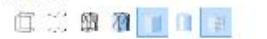 \\
\hline & File & TFATRO_VFI ARIO.obj \\
\hline & Far:s & 5.59746 \\
\hline & Vertices & 276279 \\
\hline
\end{tabular}

Figure 14. The subparts of 3D reconstructed model, showing number of faces and vertices

\section{CONCLUSION AND FUTURE WORKS}

The proposed study shows how it is possible to develop a high quality $3 \mathrm{D}$ model semantic-aware, able to connect geometrical survey of evidences with historical sources that allowed and validated the reconstruction. In this way, a centralized model could serve as comprehensive dataset of information for several goals, particularly for archaeological excavation campaign and for dissemination purposes. Moreover, the geometric accuracy obtained ensures also reliable visualization outputs.

Another aim in the present research is to obtain interactive libraries of classical elements, starting from point clouds or from archaeological traditional survey. Their benefit consists in showing construction rules, related to De Architectura, and highlighting the percentage of the $3 \mathrm{D}$ visualisation work into the assessment and interpretation of the sources, the so-called reliability of model. This is a crucial point in Virtual Archaeology (VA): several studies faced this issue and created rich contents and 3D models, however further practical implementations of Sevilla guidelines are needed. Thanks to the new 3D models, scientifically validated, such as the Theatre of Fano, the reconstruction work depicts complex contexts relating to the past or forward readings of historical, architectural or social situations. Our work, combining theoretical and technological approach, constitutes a valid contribution to the transposition of knowledge-based contents, thus proposing a powerful instrument for the cultural transmission.

In wider terms, the aim of this work is to contribute into the discussion about interactive solutions to serve archaeologist, architectural scholars and tourists. AR allows discovering, in an alternative way, monuments or ruins by simply scanning the neighbouring, loading contents from a remote repository and visualizing virtual objects. The paper analyses how contents and standards management can be performed and, thanks to comparison with state of art methods, how they can be enhanced. 
MAR experience of 3D model about complex historical architecture, using open source platforms, took its first steps. The present experience shows that further developments are needed in segmentation of model, semantical generation of contents and LOD management. Indeed the visualization of $3 \mathrm{D}$ reconstructions models is still an active issue considering the wide variety of displaying and interaction devices for immersive and augmented reality.

\section{ACKNOWLEDGEMENTS}

The authors want acknowledge Professor Paolo Clini for the scientific supervision and Professor Antonio Monterroso for the advising in $3 \mathrm{D}$ reconstruction.

The data of archaeological samples about Fano's theatre are by the Archaeological Superintendence of Marche. All data are collected within the framework of "ArcheoFano project", developed by Vitruvian Study Center, Polytechnic University of Marche, Archaeological Superintendence of Marche, Fano Municipality, funded by Pesaro and Urbino Province.

The in-depth analysis about the Fano's theatre and the Vitruvius' heritage are from the $\mathrm{PhD}$ dissertation by Daniela Amadei "L'ordine e la geometria nel teatro antico. Diffusione e fortuna del De Architectura di Vitruvio", supervisor Paolo Clini. The first 3D model of reconstruction was carried out by Renato Angeloni in his Degree thesis "Fano Roman Theatre: from the laser scanning survey to the reconstruction of a scientific model and new method to fruition".

For the database and the web development of the AR App, authors want to acknowledge Mirco Sturari.

\section{REFERENCES}

Apollonio, F. I., Gaiani, M. \& Baldissini, S., 2011. Construction, Management and Visualization of 3D Models for Cultural Heritage GIS Systems. Digital Media and its Application in Cultural Heritage, pp. 283-299.

Bernardini, A., Delogu, C., Pallotti, E. \& Costantini, L., 2012. Living the Past: Augmented Reality and Archaeology. s.l., IEEE, pp. 354-357.

Borra, D., 2004. Sulla verità del modello 3D. Un metodo per comunicare la validità dell'anastilosi virtuale. Ancona, CLUA, pp. 132-137.

Brondi, R., Carrozzino, M., Tecchia, F. \& Bergamasco, M., 2012. Mobile augmented reality for cultural dissemination. Firenze, s.n., pp. 113-117.

Choudary, O., Charvillat, V., Grigoras, R. \& Gurdjos, P., 2009. MARCH: mobile augmented reality for cultural heritage. s.1., ACM, pp. 1023-1024.

Clini, P., Frontoni, E., Quattrini, R. \& Pierdicca, R., 2014. Augmented reality experience: from high-resolution acquisition to real time augmented contents. Advances in Multimedia, p. 18.

Eggert, D., Hücker, D. \& Paelke, V., 2014. Augmented reality visualization of archaeological data. In: Cartography from Pole to Pole. Selected Contributions to the XXVIth International Conference of the ICA, Dresden 2013. Berlin Heidelberg: Springer-Verlag, pp. 203-216.

Empler, T., 2015. APP design con uso della realtà aumentata per la divulgazione dei Beni Culturali. Disegnare, pp. 60-69.
Forte, M., 2010. Introduction to Cyberarcheology, s.1.: s.n.

Gaiani, M., Benedetti, B. \& Apollonio, F. I., 2011. Teorie per rappresentare e comunicare i siti archeologici attraverso modelli critici. 1(2), pp. 33-70.

Gartner, 2015. Gartner. [Online] Available at: http://www.gartner.com/it-glossary/augmentedreality-ar

Gerval, J. P. \& Le Ru, Y., 2015. Fusion of Multimedia and Mobile Technology in Audioguides for Museum and Exhibitions. In: Fusion of Smart, Multmedia and Computer Gaming Technologies. s.l.:Springer International Publishing, pp. 173-205.

Grande, A. \& Lopez-Menchero, V., 2011. The implementation of an international charter in the field of virtual archaeology.

Haegler, S., Müller, P. \& Van Gool, L., 2009. Procedural modeling for digital cultural heritage. Journal on Image and Video Processing, p. 7.

Haugstvedt, A. \& Krogstie, J., 2012. Mobile augmented reality for cultural heritage: A technology acceptance study. s.1., IEEE, pp. 247-255.

Laudazi, A. \& Bocaccini, R., 2014. Augmented museums through mobile apps. In: EPC 2014 Horizon 2020 and Creative Europe vs Digital Heritage: A European Projects Crossover. Florence: CEUR-WS.org, pp. 12-17.

Madeleine, S., 2015. Le théâtre de Pompée à Rome: restitution de l'architecture et des systèmes mécaniques,. Caen.: Collection Quaestiones.

Moitinho, V. \& Barcelò, J. A., 2012. Understanding Virtual Objects through Reverse Engineering. Virtual Archaeology Review, 3(7), pp. 14-17.

Monterroso, A., 2010. Theatrum Pompei. Forma y arquitectura de la génesis del modelo teatral de Roma. Madrid: Consejo Superior de Investigaciones Científicas, Madrid..

Pierdicca, R. et al., 2015. Making Visible the Invisible. Augmented Reality Visualization for 3D Reconstructions of Archaeological Sites. Augmented and Virtual Reality, pp. 25-37.

Pierdicca, R. et al., 2015. Development of a GIS environment for archaeological multipurpose applications: the Fano historic centre. Capri, Heritage and Technology. Mind, Knowledge, Experience, pp. 588-597.

Pietroni, E., Forlani, M. \& Rufa, C., 2015. Livia's Villa Reloaded: An Example of Re-use and Update of a Pre-existing Virtual Museum, Following a Novel Approach in Storytelling Inside Virtual Reality Environments. Granada, IEEE.

Remondino, F., 2011. Heritage recording and 3D modeling with photogrammetry and 3D scanning. Remote Sensing, 3(6), pp. 1104-1138.

Vanoni, D., Seracini, M. \& Kuester, F., 2012. ARtifact: TabletBased Augmented Reality for Interactive Analysis of Cultural Artifacts. s.1., IEEE, pp. 44-49.

Wolfenstetter, T., 2007. Applications of augmented reality technology for archaeological purposes., s.1.: s.n. 